regimen comprises penicillin, 12-20 megaunits daily in divided doses, switching after 72 hours to a tetracycline (doxycycline $100 \mathrm{mg}$ twice daily) or erythromycin $500 \mathrm{mg}$ four times daily for 7-10 days; gentamicin is also given, $2-5 \mathrm{mg} / \mathrm{kg}$ body weight daily in divided doses, together with rectal metronidazole $500 \mathrm{mg}$ twice daily for 10 days. Cephalosporins have a lesser role as they are not effective against chlamydia. Penicillinase producing Neisseria gonorrhoeae may be managed with cefoxitin in an intramuscular dose of 1-2 $\mathrm{g}$ six hourly.

The patient may also need her blood volume restored and the electrolyte and fluid balance corrected, thereby ensuring an adequate urine output. The development of a pelvic abscess needs prompt and adequate drainage. Treatment should be continued until the clinical signs abate, while measurements of the erythrocyte sedimentation rate may be used to monitor progress.

Milder acute salpingitis may be treated either in hospital or at home, with doxycycline $100 \mathrm{mg}$ daily for 14 days and rectal metronidazole $500 \mathrm{mg}$ twice daily for 7-14 days. If the patient is pregnant erythromycin should be substituted for the doxycycline at $500 \mathrm{mg}$ four times a day for 7-14 days.

It is important to treat the initial episode adequately and correctly. Inadequate treatment will lead to sterility and chronic pelvic inflammatory disease. One episode of acute salpingitis may lead to infertility in $13 \%$ of cases and the proportions for a second and third episode are $31 \%$ and $35 \%$ respectively. ${ }^{19}$ Contact tracing and treatment are especially important in preventing this condition, as no fewer than half of male partners have definite gonococcal and chlamydial infection. $^{3}$

STUART L STANTON

Consultant Gynaecologist, Department of Gynaecology,

St George's Hospital, London SW17 0RE

1 Westrom $\mathrm{L}$. Incidence, prevalence and trends of pelvic inflammatory disease and its consequences in industrialised countries. Am $\mathcal{J}$ Obstet Gynecol 1980;139:880.

2 Kinghorn G, Duerden B, Hafiz S. Clinical and microbial investigation of women with acute salpingitis and their consorts. Brf Obstet Gynaecol 1986;93:869-80.

3 Magnusson S, Oskarsson T, Gersson R, Sveinsson B, Steingrimsson O, Thorarinsson H. Lower genital tract infection of Chlamydia trachomatis and Neisseria gonorrhoea in Icelandic women with salpingitis. Am $\mathcal{F}$ Obset Gynecol 1986;155:602-7.

4 Mardh P. Microbial etiology of pelvic inflammatory disease. Sex Transm Dis 1984;11 (suppl): 428-98.

5 Monif G. Choice of antibiotics and length of therapy in the treatment of acute salpingitis. Am $\mathcal{J}$ Med 1985;78:188-93.

6 Toth A, Lesser M, Labriola D. Development of infections of the genito-urinary tract in wives of infertile males and possible role of spermatozoa in development of salpingitis. Surg Gynecol Obstet 1984;159:565-9.

7 Jacobson L, Westrom L. Objectivized diagnosis of acute pelvic inflammatory disease. Am $\mathcal{f}$ Obstet Gynecol 1969;105:1088.

8 Paavonen J, Aine R, Teisala K, Heinonen P, Punnonen R. Comparison of endometrial biopsy and peritoneal fluid cytologic testing with laparoscopy in the diagnosis of acute pelvic inflammatory disease. Am J Obstet Gynecol 1985;151:645-50.

9 Westrom L. Effect of acute pelvic inflammatory disease on fertility. Am $\mathcal{J}$ Obstet Gynecol 1975;121:707-13.

\section{British Society of Gastroenterology: golden jubilee}

The gut has just not had the same cachet as the brain or heart. Plato rated it well below the other two and so has almost everybody else since. Neurologists and cardiologists are thought to be smart. In modern folklore brain and heart surgeons are at the top of the surgical tree, their work tailor made for colour supplement celebration. The gut and all its works? Forget it.

For the public the gut still has an image problem; for doctors it has become the exciting place to be. Fifty years ago the gut may have been "invisible, impalpable, and, except at both ends, inaccessible" - in the words of Sir Francis Avery Jones. Today, thanks to fibreoptic endoscopy, biopsy, and imaging techniques, it is almost fully charted. This process has been coordinated in Britain by the British Society of Gastroenterology.

Sir Arthur Hurst (1879-1944) was the first British doctor to take the gut seriously. His enthusiasm fired others, and in 1937 he formed the Gastroenterological Club, which in its early days resembled, perhaps appropriately, a gentlemen's dining club. Exclusivity was one of its features-even in 1952 (by which time the club had become the British Society of Gastroenterology) it agreed that "the society should be kept as small as possible and should consist only of people really interested and active in gastroenterology." That year it increased its number of ordinary members to 65 .

From the beginning it was not too exclusive to admit radiologists, biochemists, pathologists, and surgeons to its membership, and one of its great strengths has been cross fertilisation among different disciplines. Later the society realised that more and more people were "really interested and active in gastroenterology," and in its golden jubilee year it has 1500 members. In Britain almost 300 consultant physicians have a special interest in gastroenterology2: after endocrinology it is the most common special interest expressed by general physicians. ${ }^{3}$ The society's academic meetings now happen twice a year and attract hundreds. For next week's golden jubilee meeting 1470 have registered.

These meetings allow scientific advances to be rapidly disseminated, a process helped by the society's journal, Gut, which started publication in 1960 aided by the $B M \mathcal{}$. In 1971 an independent charity was formed to raise funds "to promote the fuller development of gastroenterological research and education." The British Digestive Foundation's assets now just top $£ 1 \mathrm{~m}$, but compared with other charities its income is miniscule given the proportion of gastroenterological disease-one in four cancers, one in 10 deaths, one in five operations, and one in five general practice consultations. ${ }^{4}$ The gut's poor public image has got to be changed. (In this respect President Reagan has done a great public relations job on the colon.)

Medically there is much to do. Reading through the collection of papers published by the society to commemorate its golden jubilee one learns much of diagnosis and treatment, of how the new territory was mapped out. ${ }^{5}$ But, as Gut's golden jubilee supplement" concludes: "However much we may have achieved, we still recognise our humiliating ignorance of the pathogenesis, pathophysiology, and even the clinical chemistry of observable abnormalities of most of the common diseases in our field. We have to admit to a paucity of successful or even rational treatments for many of the diseases under our care. Much remains to be conquered." 6

We wish them well.

ToNy Delamothe Assistant editor, $B M \mathcal{F}$

1 Sladen GE. Membership of the BSG 1937-1987. Gut 1987;28:(jubilee suppl):16-7.

2 Department of Health and Social Security, Medical Manpower and Education Division. Medical and dental staffing prospects in the NHS in England and Wales in 1986. Health Trends 1987; 19:1-8.

3 Houghton J, Richings J. The second specialty of general physicians. $\boldsymbol{f} R$ Coll Physicians Lond 1981;15:28-31.

4 Sarner M. The British Digestive Foundation. Gut 1987;28 (jubilee suppl):46-7.

5 British Society of Gastroenterology. A selection of scientific papers. Welwyn Garden City: Smith Kline and French Laboratories Ltd, 1987.

6 Alexander-Williams J, Baron JH. British Society of Gastroenterology 1937-87: an overview. Gut 1987;28 (jubilee suppl):53-5.

^Gut's Jubilee Supplement is available from the Publishing Manager, $B M \mathcal{f}$, price £10. It contains a history of the British Society of Gastroenterology and biographies of its leading members. 